\title{
Dissemination of Online Diagnostic Test Instrument to Diagnose High School Students' Mathematical Representation Ability: The Case of Work and Energy
}

\author{
Awal Mulia Rejeki Tumanggor ${ }^{1 *}$, Supahar ${ }^{2}$ \\ ${ }^{1}$ Master of Physics Education, Faculty of Mathematics and Natural Sciences, Universitas Negeri Yogyakarta, \\ Indonesia \\ ${ }^{2}$ Department of Physics Education, Faculty of Mathematics and Natural Sciences, Universitas Negeri \\ Yogyakarta, Indonesia \\ *Corresponding author. Email: awalmrt94@gmail.com
}

\begin{abstract}
Diagnostic test instruments used to detect students' mathematical representation abilities and adjusted to the main principles of mathematical representation abilities, is students can determine the right equation according to the problem and operationalize mathematical equations to solve problems. This research aims to disseminate valid, reliable, and effective diagnostic test instruments for use in physics learning, especially to diagnose mathematical representation abilities. The assessment is based on the results of developing an online web-assisted student's mathematical representation ability instrument. This research uses the Research and Development (R\&D) method which is carried out by taking samples from several high schools in the Bantul Regency. The product was applied to 63 students from two schools in Bantul Regency, Special Region of Yogyakarta with the Cluster Random Sampling (Area Sampling) technique. The development model in this research is the 4D model. The 4D model combined with Oriondo \& Dallo-Antonio is implemented through the Define, Design, Develop and Disseminate stages. The research results are (1) the dissemination results of valid diagnostic test instruments to diagnose the mathematical representation ability with $\mathrm{V}$-Aiken coefficient of 0.86 to 1 , and reliability can be categorized as "Excellent", (2) The results of the dissemination to determine the profile of students' abilities can be categorized "Medium" in terms of the student ability distributions, and (3) the practicality level of the PhysDTRA product assessment was categorized as "Very Good" according to the assessment by the teacher and student responses.
\end{abstract}

Keywords: Dissemination, Diagnostic instrument, Mathematical representation, Online, Work and energy

\section{INTRODUCTION}

One of the important abilities in the 21 st century needs that must be prepared to become a competitive human being is the problem-solving skill. Physics learning that has been received should provide experience for students so that they have the ability to build, understand, and establish the physics concepts that have been learned to solve problems [1], [2]. problem-solving is always related to learning physics because every discussion of physics requires solving problems that are synergistic in it [3], [4].
Docktor \& Mestre [5] define representation as a solution to solving physics problems. The representation in question can be presented in image, analogy, mathematical, diagrammatic, vector and verbal formats related to the concept of physics [6]. One representation that can solve physics problems is a mathematical representation [7]. The same thing was also presented by Kohl \& Finkelstein [8] that to solve physics problems it is necessary to use verbal problems in the form of pictures, and ends with the use of mathematical formulas in solving problems. Mathematical abilities are needed to explain how equations are used differently in the context of 
physics, but the performance for solving calculation problems is worse than other formats [5]. Mathematical representation in physics is the description of variable values which includes equations and functions to explain the physical state of an event. Treagust, Duit \& Fischer [9] explain that mathematical learning uses a lot of symbolic quantities and thematic proofs, whereas physics is a subject that involves many abstract formulas. Work and energy are physics materials that can identify students' mathematical representation abilities. Neumann [10] argues that students still have difficulty in pouring ideas and concepts of work and energy into mathematical equations.

The results of the 2018 PISA (Programme for International Student Assessment) study explained that the performance of students' abilities in Indonesia has decreased from the three aspects measured when compared to 2015. One of the three aspects measured is a mathematical ability which is closely related to mathematical representation [11]. The decline in student ability is an evaluation for teachers and education practitioners in planning appropriate learning to improve student abilities and competencies. One of the concerns for increasing competence is improving the assessment system. Appropriate assessments need to be designed and focused on detecting student weaknesses and difficulties. The results of the assessment will also be reported in a form that is useful for improving classroom teaching practices and the formulation of education policies. The teacher's effort in detecting students' difficulties and weaknesses is a challenge in learning [12]. One form of assessment to detect student weaknesses is to do a diagnostic assessment [13].

The challenge in implementing diagnostic assessments is that teachers must adapt learning to the needs and character of students. The diagnostic assessment focuses on analyzing students' incorrect answers on the items being measured. The analysis that is carried out must measure the ability of students at the individual level [14], [15]. Time and implementation limitations for a large number of students in learning are one of the reasons for the difficulty of conducting diagnostic assessments. Therefore, we need a media that helps teachers and education practitioners in carrying out diagnostic assessments. One of them is by using a website-based online assessment. The use of online assessment media can help teachers analyze student answers and provide suggestions so that assessment activities are more effective and efficient [16]-[18]. The advantage of using this online assessment media is that it can be accessed easily at certain times and places [19], [20]. In addition, the 4.0 industrial revolution encourages automation systems in all activity processes. This change has an impact on the world of education, especially in the assessment system.

Therefore, it is necessary to assess the dissemination of the development results of an online diagnostic test instrument which has a characteristic form of suggestions contained in each answer choice so that it can diagnose the mathematical representation ability of high school students on the Work and Energy.

\section{RESEARCH METHODS}

This research is a research development. The development stages follow 4D model (Define, Design, Develop, Disseminate) [21] with the Oriondo \& DalloAntonio development model which includes: 1) Planning the Test, 2) Trying out, 3) Establishing Test Validity, 4) Establishing Test Reliability, and 5) Interpreting the Test Score [22].

The dissemination stage of this research is the field trying out stage to ensure product development in the form of a diagnostic test instrument combined with web-based online media to be effective when viewed from the results of the study of product practicality by teachers and student responses to product use. After that, the product can be implemented to determine the ability profile of students. The development procedure of the test instrument and product is shown in Figure 1.

\subsection{Population}

The dissemination stage was implemented online in September 2020, involving 63 students in two high schools located in Bantul Regency, Yogyakarta Special Region with the Cluster Random Sampling (Area Sampling) technique. The two schools are SMA Negeri 1 Sewon and SMA Negeri 3 Bantul.

\subsection{Data Collection}

Product implementation is carried out using a valid and reliable diagnostic test instrument of 21 questions of mathematical representation, after which it is combined in an online assessment media in the form of a web called PhysDTRA (Physics Diagnostic Test for Mathematical Representation Ability). PhysDTRA instruments were distributed to obtain profiles of students' mathematical representation abilities. Practicality review sheets for PhysDTRA products 
will be distributed to determine the responses of teachers and students after using these products.

\subsection{Data Analysis}

The assessment of the student response questionnaire and the teacher's response results to the practicality of working with web-assisted instruments is said to be feasible if the instrument is in a good category. The assessment step carried out changes the scale of the statement to a value scale. The explanation is as follows: $\mathrm{No}=0$ and Yes $=1$. Data tabulation will be carried out from all data obtained from the assessment instrument component. Descriptive analysis was carried out using the following equation [23]:

$$
\overline{\mathrm{X}}=\frac{\sum \mathrm{X}}{\mathrm{n}}
$$

Description; $n$ is the number of raters, $\sum \mathrm{X}$ is the number, and $\bar{X}$ is the mean score. The next step is to interpret the mean score into a value with the category for changing the score as shown in Table 1 [24].

Table 1. Categorization of assessment score

\begin{tabular}{|l|l|l|}
\hline No & Test Parameter & Category \\
\hline 1 & $X>\bar{X}_{i}+1.8 \mathrm{Sb}_{i}$ & Very Good \\
\hline 2 & $\bar{X}_{i}+0.6 \mathrm{Sbi}<\mathrm{X} \leq \bar{X}_{i}+1.8 \mathrm{Sbi}$ & Good \\
\hline 3 & $\bar{X}_{i}-0.6 \mathrm{Sbi}<\mathrm{X} \leq \bar{X}_{i}+0.6 \mathrm{Sbi}$ & $\begin{array}{l}\text { Good } \\
\text { Enough }\end{array}$ \\
\hline 4 & $\bar{X}_{i}-1.8 \mathrm{Sbi}<\mathrm{X} \leq \bar{X}_{i}-0.6 \mathrm{Sbi}$ & Less \\
\hline 5 & $\mathrm{X} \leq \bar{X}_{i}-1.8 \mathrm{Sbi}$ & Very Less \\
\hline
\end{tabular}

Description; $\mathrm{X}$ is actual score, $\overline{\mathrm{X}}_{\mathrm{i}}$ is ideal mean = $1 / 2$ (ideal maximum score + ideal minimum score). $\mathrm{Sb}_{\mathrm{i}}$ is ideal standard deviation $=1 / 6$ (ideal maximum score - ideal minimum score).

Categorization table of assessment score also applies to determine the assessment category of students' abilities by changing the description of the categories to Very Low, Low, Medium, High and Very High.

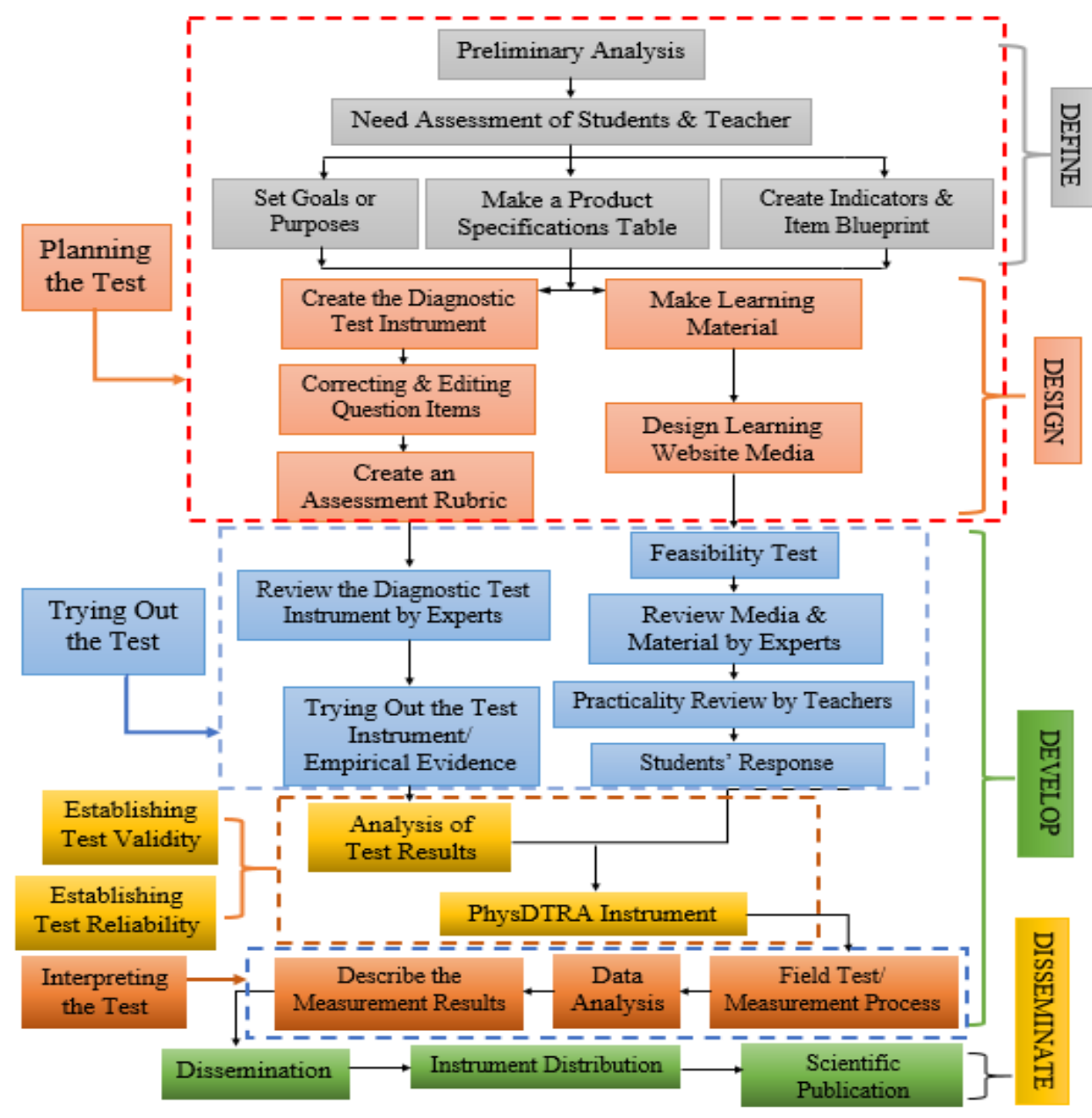


Figure 1. Research and development procedure

\section{RESULT AND DISCUSSION}

Students at the high school level /equivalent should be able to select, use and translate mathematical representations to solve problems because students who have mathematical representation ability will be more critical in evaluating their understanding [4], [25]. Mathematical representation is defined as a format used to describe problems into a mathematical model and its relationship between variables [26]. Based on the opinion of some researchers, the synthesis of mathematical representation indicators can be shown as in Table 2 [27]. One of the 21 items of test instruments developed to diagnose student's mathematical representation ability in the Work and Energy subject is shown in Table 3. This item instrument follows the cognitive level C4 (Analyzing) from A revision of Bloom's Taxonomy.

Diagnostic test instruments to detect students' mathematical representation abilities have gone through the content validity stage and empirical tests to determine the validity and reliability of the test instruments. The content validation coefficient was assessed by expert judgment and declared valid based on the V-Aiken equation [28] with a minimum value of 0.86 . Furthermore, based on empirical tests, the diagnostic test instrument has been reliable with the item reliability results of 0.95 . This shows that the diagnostic test instrument is ready to be implemented in learning.

The product made is an online web-based which is used as a forum for conducting diagnostic assessments with questions that have a diagnosis and suggestions for each answer choice. There are 21 items of valid and reliable diagnostic test instruments to be combined in an online web-based and named the product PhysDTRA (Physics Diagnostic Test for Mathematical Representation Ability). 21 items are divided based on 4 indicators of mathematical representation ability and divided into 3 meetings based on sub-material of the Work and Energy. PhysDTRA products can be accessed using a PC (Personal Computer) or a Smartphone. PhysDTRA product display can be seen in Figure 2.

After the PhysDTRA product has been designed, the product will then be reviewed in the form of media validation by a media expert. The media expert consisted of 7 experts consisting of assessment experts, physics learning experts, physicists, 2 physics education evaluation practitioners, and 2 peer reviewers. The results of the analysis of the media validation analysis or PhysDTRA products obtained the "Very Good" category results. And several product reviews have been revised for product improvement.

In the next step, to ensure the practical assessment aspects of using PhysDTRA products, the results of the study in the form of assessments and input to PhysDTRA products were given by 12 physics teachers throughout Yogyakarta in the UNY 2020 Postgraduate Community Service (PPM) activities. The results of the assessment stated that PhysDTRA products were practical. can be used well. However, there is a suggestion from the reviewer that the time efficiency on each item must be clear, which is 2 minutes and when the time runs out it will automatically proceed to the next question. Improvements have been made to PhysDTRA products from the teachers' reviews. Data on the results of PhysDTRA product assessments by education practitioners (teachers) can be seen in Table 4 .

Table 2. Mathematical representation ability synthesis results

\begin{tabular}{|c|c|c|c|c|c|}
\hline \multirow[b]{2}{*}{ Aspect } & \multirow[b]{2}{*}{ Sub-Aspect } & \multirow[b]{2}{*}{ Indicator } & \multicolumn{3}{|c|}{ Sub-Material } \\
\hline & & & Work & $\begin{array}{l}\text { Kinetic \& } \\
\text { Potential } \\
\text { Energy }\end{array}$ & $\begin{array}{l}\text { Conservation of } \\
\text { Mechanical } \\
\text { Energy }\end{array}$ \\
\hline \multicolumn{3}{|c|}{ Mathematical Representation Ability } & Meeting 1 & Meeting 2 & Meeting 3 \\
\hline \multirow{2}{*}{$\begin{array}{l}\text { Interpret } \\
\text { Data }\end{array}$} & $\begin{array}{l}\text { Interpreting } \\
\text { Variable }\end{array}$ & $\begin{array}{l}\text { Students are able to interpret variables } \\
\text { according to concepts in the form of } \\
\text { pictures, tables, diagrams, and graphs to } \\
\text { solve problems. }\end{array}$ & 1,2 & 8,9 & 15,16 \\
\hline & $\begin{array}{l}\text { Associating } \\
\text { Variables }\end{array}$ & $\begin{array}{l}\text { Students are able to connect the variables } \\
\text { contained in a problem in the form of } \\
\text { images, tables, diagrams, and graphs to } \\
\text { solve problems. }\end{array}$ & 3,4 & 10,11 & 17 \\
\hline
\end{tabular}




\begin{tabular}{|l|l|l|l|l|l|}
\hline \multirow{2}{*}{ Aspect } & \multirow{2}{*}{ Sub-Aspect } & Indicator & Sub-Material & \multicolumn{3}{|l|}{$\begin{array}{l}\text { Kinetic \& } \\
\text { Potential } \\
\text { Energy }\end{array}$} & $\begin{array}{l}\text { Conservation of } \\
\text { Mechanical } \\
\text { Energy }\end{array}$ \\
\hline \multirow{2}{*}{$\begin{array}{l}\text { Operate } \\
\text { Equation }\end{array}$} & $\begin{array}{l}\text { Operate } \\
\text { Data }\end{array}$ & $\begin{array}{l}\text { Students are able to operate equations } \\
\text { appropriately in the form of numbers, } \\
\text { symbols, or pictures in solving problems. }\end{array}$ & 5,6 & 12 & 18,19 \\
\cline { 2 - 7 } & $\begin{array}{l}\text { Formulate } \\
\text { Results }\end{array}$ & $\begin{array}{l}\text { Students are able to conclude conditions } \\
\text { with mathematical equation operations to } \\
\text { get results. }\end{array}$ & 7 & 13,14 & 20,21 \\
\hline
\end{tabular}

Table 3. Item Test Instrument to Diagnose Mathematical Representation Ability

\begin{tabular}{|c|c|c|}
\hline Item II & Question Number 6 & olution \\
\hline $\begin{array}{l}\text { Presented an } \\
\text { illustrative } \\
\text { image of an } \\
\text { object on a flat } \\
\text { plane, students } \\
\text { can operate the } \\
\text { Work equation } \\
\text { on the system } \\
\text { appropriately. }\end{array}$ & $\begin{array}{l}\text { An object is placed on a horizontal plane, } \\
\text { then pushed with a force } F \text { so that it } \\
\text { experiences a displacement } \Delta \mathbf{x} \text { with the } \\
\text { friction coefficient } \mu_{\mathrm{g}} \text { as shown below. } \\
\text { The work } W \text { equation in the system is... } \\
\text { a. } W=\left(\mathbf{F} \cos \theta-\mu_{g} \mathbf{N}\right) \Delta \mathbf{x} \\
\text { b. } W=\left(\mathbf{F} \sin \theta-\mu_{g} \mathbf{N}\right) \Delta \mathbf{x} \\
\text { c. } W=\left(\mathbf{F} \cos \theta-\mu_{g} \mathbf{N}\right) \mathbf{s} \\
\text { d. } W=\left(\mathbf{F} \sin \theta-\mu_{g} \mathbf{N}\right) \mathbf{s} \\
\text { e. } W=\left(\mu_{g} \mathbf{N}-\mathbf{F} \sin \theta\right) \Delta \mathbf{x}\end{array}$ & $\begin{array}{l}\text { Answer: } \mathrm{B} \\
\text { - Answer: } \\
\text { Projection of } F \text { about the } x \text {-axis: } \\
\text { - The work } W \text { equation: } \\
\qquad \begin{array}{l}W=\sum \mathbf{F} \sin \theta \\
W=\left(\mathbf{F}_{x}-\mathbf{f}_{\mathrm{g}}\right) \Delta \mathbf{x}\end{array} \\
\text { After all variables have been substituted, it is obtained: } \\
W=\left(\mathbf{F} \sin \theta-\mu_{g} \mathbf{N}\right) \Delta \mathbf{x}\end{array}$ \\
\hline & Diagnostics & Advice \\
\hline $\begin{array}{l}\text { If you choose C: } \\
\text { Students have } \\
\text { develop equatic } \\
\text { process of pro } \\
\text { displacement an }\end{array}$ & $\begin{array}{l}\text { lour Answer is Wrong } \\
\text { ot been able to describe variables and } \\
\text { s appropriately, a mistake occurs in the } \\
\text { ecting the Force to the direction of } \\
\text { our Answer is Wrong } \\
\text { ot been able to describe variables and } \\
\text { s appropriately, a mistake occurs in the } \\
\text { ecting the Force to the direction of } \\
\text { the use of variables that are still wrong. }\end{array}$ & $\begin{array}{l}\text { If you choose A: } \\
\text { You should learn how to project the direction of the } \\
\text { force against the direction an object is moving to be } \\
\text { able to develop the equation precisely. } \\
\text { If you choose C: } \\
\text { You should learn how to project the direction of the } \\
\text { force against the direction an object is moving and use } \\
\text { the correct variables to be able to develop the equation } \\
\text { correctly. } \\
\text { If you choose D: }\end{array}$ \\
\hline
\end{tabular}


Students have been able to describe variables and develop equations appropriately, but there is an error with the displacement variable which should be expressed as $\Delta x$.

If you choose E: Your Answer is Wrong

Students have not mastered the Work concept which is influenced by force and displacement, so they have not been able to describe variables and develop equations correctly.
You should be more careful in reviewing the examples or alternations of variables that affect the development of the equation.

\section{If you choose $\mathrm{E}$ :}

You should review the concept of work caused by the force-producing displacement, to be able to develop the equation correctly.

Table 4. Analysis Results of Product Practicality by The Teachers

\begin{tabular}{|l|l|l|l|}
\hline Aspect & Sub-Aspect & Average & Criteria \\
\hline Product Display & Instructions for use of PhysDTRA product & 0.89 & Very Good \\
\hline \multirow{3}{*}{ Software Engineering } & Ease of Access & 0.89 & Very Good \\
\cline { 2 - 4 } & Creativity and Innovation & 0.92 & Very Good \\
\hline \multirow{4}{*}{ Learning } & Suitability of indicator with KI, KD and curriculum & 1 & Very Good \\
\cline { 2 - 4 } & Suitability of learning objectives with indicators & 1 & Very Good \\
\hline & Explanation of the material concept & 1 & Very Good \\
\cline { 2 - 4 } & Accuracy of using the language & 1 & Very Good \\
\cline { 2 - 4 } & Suitability of writing question formulations & 1 & Very Good \\
\cline { 2 - 4 } & Suitability of the answer key to the question & 1 & Very Good \\
\cline { 2 - 4 } & Suitability of the diagnosis with the questions & 1 & Very Good \\
\cline { 2 - 4 } & Suitability of advice with diagnosis & 1 & Very Good \\
\hline \multirow{2}{*}{ TOTAL } & & 0,97 & Very Good \\
\hline
\end{tabular}

Table 5. Students' Response Results

\begin{tabular}{|l|l|l|l|}
\hline \multirow{3}{*}{ Aspect } & Sub Aspect & Average & Criteria \\
\hline \multirow{3}{*}{ Product Display } & A Positive Impression on Display Quality & 0.87 & Very Good \\
\cline { 2 - 4 } & A Positive Impression on The Illustration Quality & 0.83 & Very Good \\
\hline \multirow{3}{*}{ Test Construction } & Ease of Program Operation & 0.90 & Very Good \\
\cline { 2 - 4 } & Ease of Use Navigation & 0.86 & Very Good \\
\cline { 2 - 4 } & Update and Interest in The Software & 0.84 & Very Good \\
\hline Language & Questions Presented Follow the Material & 0.83 & Very Good \\
\hline \multirow{2}{*}{ TOTAL } & Ease of Language Use & 0.95 & Very Good \\
\hline Aspect & & 0,86 & Very Good \\
\hline \multirow{3}{*}{ Product Display } & Sub Aspect & Average & Criteria \\
\hline \multirow{4}{*}{ The Functionality of Use } & A Positive Impression on Display Quality & 0.87 & Very Good \\
\cline { 2 - 5 } & A Positive Impression on The Illustration Quality & 0.83 & Very Good \\
\hline & Ease of Program Operation & 0.90 & Very Good \\
\cline { 2 - 4 } & Ease of Use Navigation & 0.86 & Very Good \\
\cline { 2 - 4 } & Update and Interest in The Software & 0.84 & Very Good \\
\hline Test Construction & Questions Presented Follow the Material & 0.83 & Very Good \\
\hline Language & Ease of Language Use & 0.95 & Very Good \\
\hline TOTAL & & 0,86 & Very Good \\
\hline
\end{tabular}




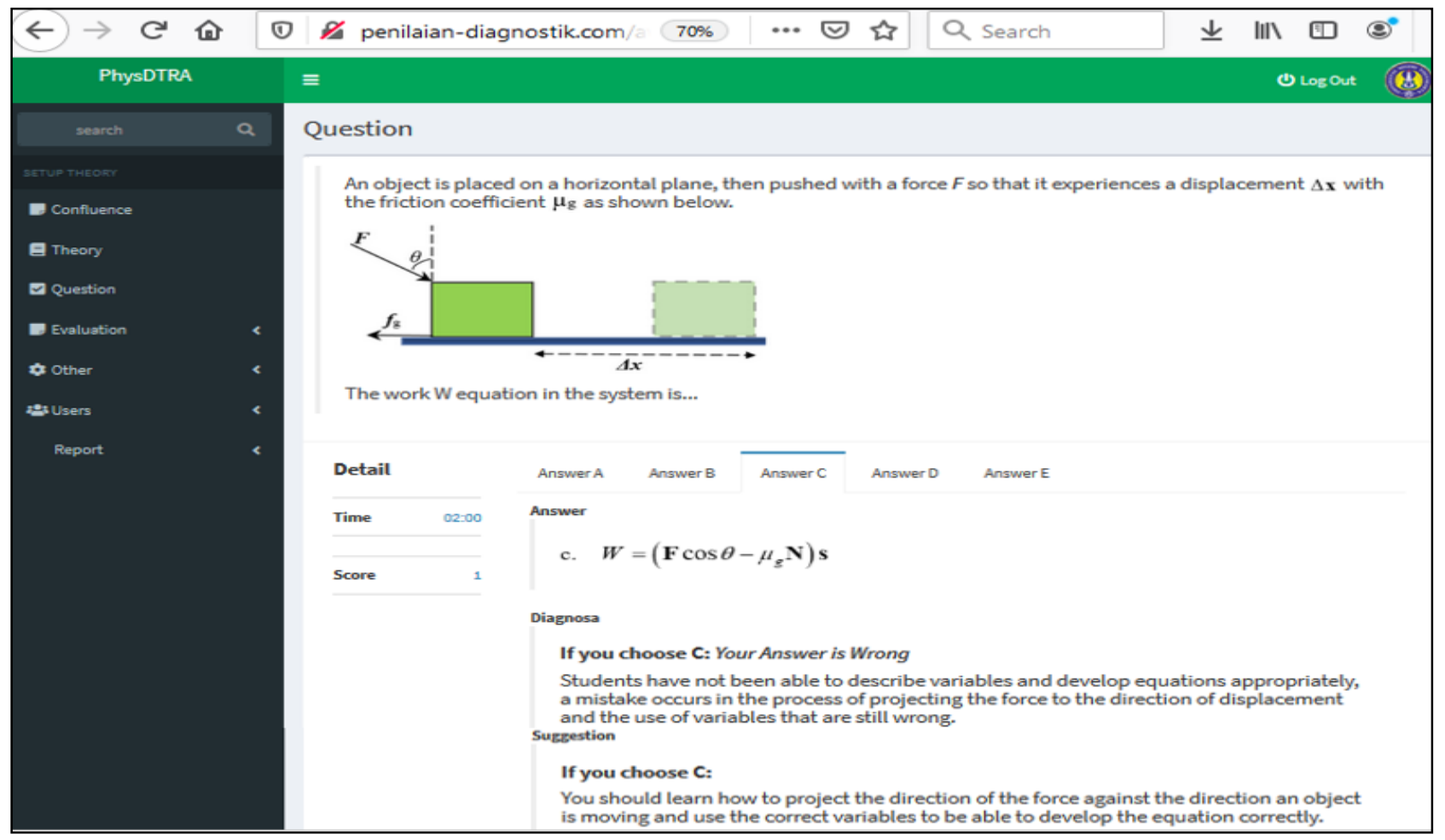

Figure 2. Product Display of PhysDTRA

The results of the calculation through the assessment category (Table 1) related to the practicality of PhysDTRA products obtained an average assessment of all aspects of 0.97 which is in the "Very Good" category. This shows that the practicality of PhysDTRA products can be used in research. The data for calculating student responses using PhysDTRA products provide in Table 5. The study result data in the form of assessments and responses from the media aspect were provided by 46 students. The results of the calculation through the assessment categories (Table 1) related to student responses to PhysDTRA products obtained an average assessment of all aspects of 0.86 which is included in the "Very Good" category. This shows that PhysDTRA products can be used in research.

The dissemination stage was carried out on 63 high school students who had studied the Work and Energy material. Students take a diagnostic test for 3 meetings with different sub-material for each meeting. Descriptive explanations are shown in Table 6 and Table 7 to analyze the representation ability profile of high school students on the work and energy material.

Table 6. Ability Measurement Results based on Aspects

\begin{tabular}{|c|c|c|c|}
\hline Aspect & Sub Aspect & Average & Criteria \\
\hline \multirow{2}{*}{$\begin{array}{l}\text { Interpret } \\
\text { Data }\end{array}$} & $\begin{array}{l}\text { Interpreting } \\
\text { Variable }\end{array}$ & 1.78 & Less \\
\hline & $\begin{array}{l}\text { Associating } \\
\text { Variables }\end{array}$ & 1.93 & Less \\
\hline
\end{tabular}

\begin{tabular}{|l|l|l|l|}
\hline Aspect & Sub Aspect & Average & Criteria \\
\hline \multirow{2}{*}{$\begin{array}{l}\text { Operate } \\
\text { Equation }\end{array}$} & Operate Data & 2.07 & Less \\
\cline { 2 - 4 } & Formulate Results & 1.95 & Less \\
\hline TOTAL & 1.93 & Less \\
\hline
\end{tabular}

Table 7. Ability Measurement Results based on Meetings.

\begin{tabular}{|l|l|l|l|}
\hline Sub Material & Meeting & Average & Criteria \\
\hline Work & 1 & 2.49 & Less \\
\hline $\begin{array}{l}\text { Potential \& Kinetic } \\
\text { Energy }\end{array}$ & 2 & 2.33 & Less \\
\hline $\begin{array}{l}\text { Conservation of } \\
\text { Mechanical Energy }\end{array}$ & 3 & 2.92 & $\begin{array}{l}\text { Good } \\
\text { Enough }\end{array}$ \\
\hline TOTAL & & 2.58 & Less \\
\hline
\end{tabular}

The results of the measurement of students' abilities are in the "Less" criteria based on the aspect of mathematical representation abilities and the number of meetings of the Work and Energy sub-material. Even though the students have taken physics lessons on Work and Energy, in reality, the condition of the students after being measured using a diagnostic test instrument is proven to be still in "Less" criteria. This proves that the diagnostic test instrument is able to diagnose student weaknesses in depth. Remediation is needed to overcome student weaknesses after attending lessons. Diagnostic test instruments really help teachers or education practitioners to diagnose student weaknesses, so that remediation by teachers is more targeted to solve student difficulties. 
Students' mathematical representation abilities are interpreted in five scales based on Table 1, namely very low, low, medium, high, and very high. The students' mathematical representation ability is theta $(\theta)$ and is shown in Figure 3.

Students' abilities can be determined from the $\mathrm{PH} 3$ and $S C O$ format files in the Parscale program output.
Students' mathematical representation abilities are presented in the ability column on the logit scale. The results of the measurement of mathematical representation ability of 63 students showed that the students" abilities were at "Medium" abilities, so that the teacher/ educator was expected to be able to properly remediate the diagnosis of student weaknesses according to the students' abilities.

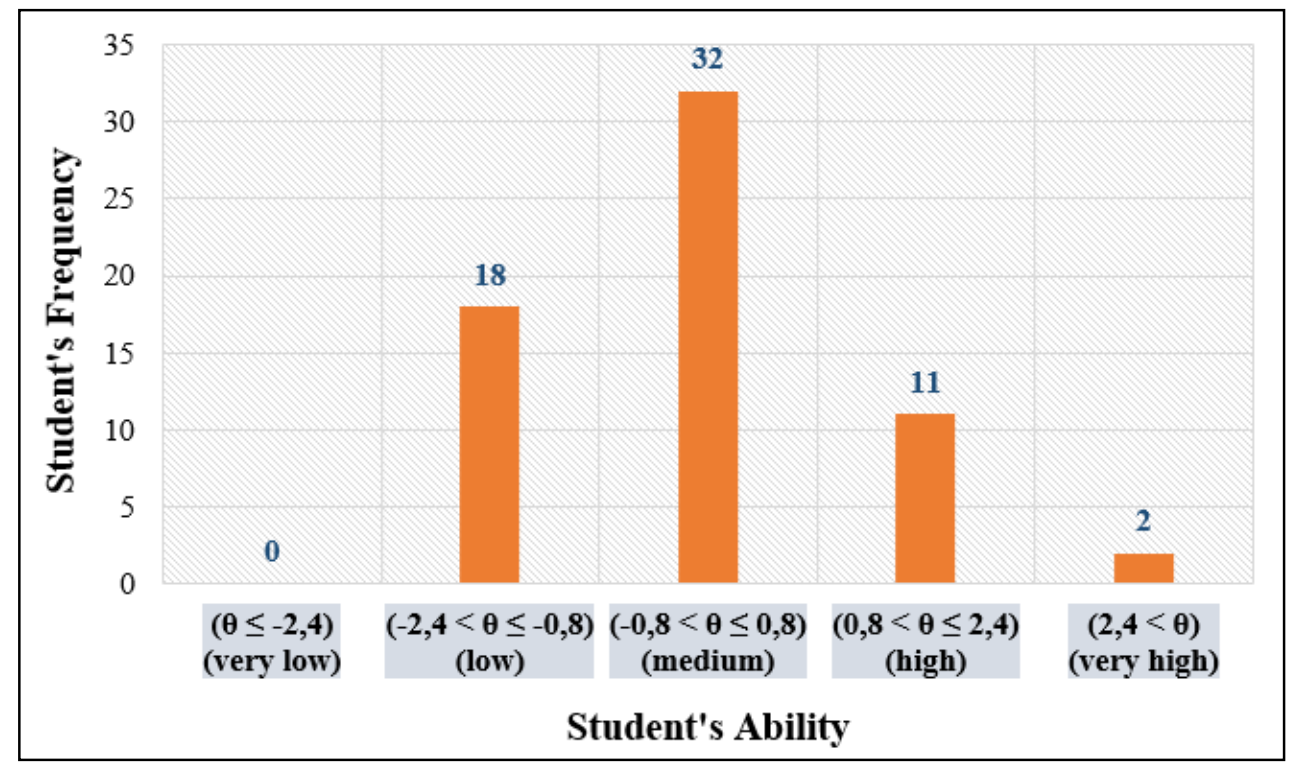

Figure 3. Histogram of estimated ability

\section{CONCLUSION}

Based on the research results and development of diagnostic test instruments, it stated that they are valid according to the judgment of experts who are analyzed using the Aiken's V equation. PhysDTRA instruments and products are also reliable based on the reliability of item and category estimations very well, so they can be used to diagnose students' mathematical representation abilities. PhysDTRA products have also met the "Very Good" category based on reviews of product practicality by teachers and student responses. Thus, the PhysDTRA instrument product developed has met the characteristics of a test that is feasible in terms of content, empirical evidence, validity, and reliability.

The results of the dissemination show that the distribution of students' mathematical representation abilities is classified into five scales according to Widoyoko, namely very low, low, medium, high, and very high (Figure 4 ). The frequency of students at $0 \%$ has very low representation abilities, and $17 \%$ with low ability categories. The frequency of students at a moderate level of mathematical representation ability is $56 \%$. Then $29 \%$ of students have a high level of mathematical representation ability, and $3 \%$ are in the very high category.

\section{AUTHORS' CONTRIBUTIONS}

A.M.R. Tumanggor analyzed the preliminary studies, developed diagnostic instrument, participated in the research design, and performed the statistical analyses. Supahar guided the whole research and coordinated the development of test instruments. All authors read and approved the final manuscript.

\section{ACKNOWLEDGMENTS}

The authors would like to thank for funding support from the Directorate of Research and Community Service (DRPM), Deputy for Strengthening Research and Development of the Ministry of Research, Technology, and Higher Education/ National Research and Innovation Agency through Masters Thesis Research, No. T/9.65/UN34.21/PT.01.03/2020.

\section{REFERENCES}

[1] B. Ibrahim, N.S. Rebello, Representational Task Formats and Problem Solving Strategies in Kinematics and Work, Physical Review Special Topics - Physics Education Research 8(1) (2012), 010126.

DOI: https://doi.org/10.1103/PhysRevSTPER.8.010126 
[2] A.M. R.Tumanggor, J. Jumadi, I. Wilujeng, E.S. Ringo, The Profile of Students' Physics Problem Solving Ability in Optical Instruments, Jurnal Penelitian \& Pengembangan Pendidikan Fisika 5(1) (2019) 29-40. DOI: https://doi.org/10.21009/1.05104

[3] A.M. Johnson, K.R. Butcher, G. Ozogul, M. Reisslein, Learning from Abstract and Contextualized Representations: The Effect of Verbal Guidance, Computers in Human Behavior 29(6) (2013) 2239-2247. DOI: https://doi.org/10.1016/j.chb.2013.05.002

[4] D.H. Jonassen, Learning to Solve Problems. Routledge, 2011.

[5] J.L. Docktor, J.P. Mestre, Synthesis of DisciplineBased Education Research in Physics, Physical Review Special Topics - Physics Education Research 10(2) (2014) 020119. DOI: https://doi.org/10.1103/PhysRevSTPER.10.020119

[6] M. De Cock, Representation Use and Strategy Choice in Physics Problem Solving, Physical Review Special Topics - Physics Education Research 8(2) (2012) 1-17. DOI: https://doi.org/10.1103/PhysRevSTPER.8.020117

[7] A. Van Heuvelen, X. Zou, Multiple Representations of Work-Energy Processes, American Journal of Physics 69(2) (2001) 184-194. DOI: https://doi.org/10.1119/1.1286662

[8] P.B. Kohl, N.D. Finkelstein, Patterns of Multiple Representation Use by Experts and Novices During Physics Problem Solving, Physical Review Special Topics - Physics Education Research 4(1) (2008) 111.

DOI: https://doi.org/10.1103/PhysRevSTPER.4.010111

[9] D.F. Treagust, R. Duit, H.E. Fischer, Multiple Representations in Physics Education, Springer International Publishing, 2017

[10] K. Neumann, T. Viering, W.J. Boone, H.E. Fischer, Towards A Learning Progression of Energy, Journal of Research in Science Teaching 50(2) (2013) 162 188. DOI: https://doi.org/10.1002/tea.21061

[11] OECD, PISA 2018 Results (Volume II), OECD Publishing, 2019.

[12] Y. Prihatni, K. Kumaidi, M. Mundilarto, Developing the Instruments of Cognitive Diagnostic for Science Subject in Junior High School, Jurnal Penelitan dan Evaluasi Pendidikan 20(1) (2016) 111-125.

DOI: https://doi.org/10.21831/pep.v20i1.7524
[13] A.M.R. Tumanggor, Supahar, H. Kuswanto, E.S. Ringo, Using four-tier diagnostic test instruments to detect physics teacher candidates' misconceptions: Case of mechanical wave concepts, in: Journal of Physics: Conference Series, vol. 1440, IOP Publishing, Bristol, 2020, pp. 1-9. DOI: https://doi.org/10.1088/1742-6596/1440/1/012059

[14] A.M.R. Tumanggor, S. Supahar, E.S. Ringo, M.D. Harliadi, Detecting Students' Misconception in Simple Harmonic Motion Concepts Using Four-Tier Diagnostic Test Instruments, Jurnal Ilmiah Pendidikan Fisika Al-Biruni 9(1) (2020) 21-31. DOI:https://doi.org/10.24042/jipfalbiruni.v9i1.457 1

[15] A.A. Rupp, J. Templin, R.A. Henson, Diagnostic Measurement: Theory, Methods, and Applications. The Guilford Press, 2010.

[16] Shudong Wang, Hong Jiao, M. J. Young, T. Brooks, J. Olson, Comparability of Computer-Based and Paper-and-Pencil Testing in K-12 Reading Assessments, Educational and Psychological Measurement 68(1) (2008) 5-24. DOI: https://doi.org/10.1177/0013164407305592

[17] S.L. Watson, W.R. Watson, The Role of Technology and Computer-Based Instruction in a Disadvantaged Alternative School's Culture of Learning, Computer in the Schools 28(1) (2011) 3955.

DOI: https://doi.org/10.1080/07380569.2011.552042

[18] S. Sfenrianto, Y.B. Hartarto, H. Akbar, M. Mukhtar, E. Efriadi, M. Wahyudi, An Adaptive Learning System based on Knowledge Level for English Learning, International Journal of Emerging Technologies in Learning 13(12) (2018) 191-200. DOI: $\underline{\text { https://doi.org/10.3991/ijet.v13i12.8004 }}$

[19] Suyoso, S. Nurohman, Developing Web-Based Electronics Modules as Physics Learning Media, Jurnal Kependidikan 44(1) (2014) 73-82. DOI: https://doi.org/10.21831/jk.v44i1.2193

[20] D. Darmaji, D. A. Kurniawan, A. Astalini, A. Lumbantoruan, S. C. Samosir, Mobile Learning in Higher Education for The Industrial Revolution 4.0: Perception and Response of Physics Practicum, International Journal of Interactive Mobile Technologies 13(9) (2019) 4-20. DOI: https://doi.org/10.3991/ijim.v13i09.10948

[21] S. Thiagarajan, Instructional Development for Training Teachers of Exceptional Children: A Sourcebook, Journal of School Psychology (1974). 
[22] L.L. Oriondo, E.M. Dallo-Antonio, Evaluating Educational Outcomes (Test, Measurement, and Evaluation), REX Printing Company Inc, 1984.

[23] Sugiyono, Quantitative, Qualitative, and R\&D Approaches, Alfabeta, 2016.

[24] E.P. Widoyoko, Assessment of Learning Outcomes in Schools Revision Edition, Pustaka Pelajar, 2018.

[25] B. Hand, M. Mcdermott, V. Prain, Using Multimodal Representations to Support Learning in the Science Classroom, Springer International Publishing, 2016.

[26] T. Nilsen, C. Angell, L.S. Grønmo, Mathematical Competencies and The Role of Mathematics in Physics Education: A Trend Analysis of TIMSS Advanced 1995 and 2008, Acta Didactica Norge 7(1) (2013). DOI: https://doi.org/10.5617/adno.1113

[27] A.M.R. Tumanggor, S. Supahar, The Development of Diagnostic Test Instrument for Mathematical Representation Ability (PhysDTRA) in High School Physics Learning, Journal for Education of Gifted Young Scientists 8(4) (2020) 1439-1453. DOI: https://doi.org/10.17478/jegys.777425

[28] L.R. Aiken, Three Coefficients for Analyzing the Reliability and Validity of Ratings, Educational Psychological Measurement 45(1) (1985) 131-142. DOI: https://doi.org/10.1177/0013164485451012 